of tea and slept the whole night, and has been doing well ever since. She experienced no shock whatever.

Remarks.-I did not allow any stimulants, such as strychnin or brandy, to be used. Morphia gr. 1/4, atropin gr. 1/150 was given at the start. I entered the abdominal cavity with the intention of giving my patient every possible chance, as 1 did not wish to infect the abdomen with a probable infectious tumor and, therefore, to endanger her life. As a general anesthetic was contraindicated it was necessary to use local anesthesia, but, in all, probably not more than 40 minims of a 4 per cent. solution of cocain was used.

The case appeals to me, for the ease in which the abdomen was entered, the absence of bad after-effect and of shock, the entire absence of any discomfort from the operation, and the wonderful manner in which the patient is continuing to recover.

\section{A FATAL CASE OF TETANUS OCCURRING WITHIN SEVENTY-TWO HOURS OF INJURY}

\section{J. B. TYRRELL, M.D., Sc.M. WATERVILLE, MINN.}

Patient.-W. D. G., boy, aged 10.

History.-On Tuesday, Aug. 15, I905, at about 6 p. m., the boy fell from a stageing to the ground, a distance of about 8 or 10 feet, and sustained a compound fracture transversely through the lower epiphysis of the tibia, the bone ripping the soft parts and stocking for a distance of 4 inches above the site of the fracture and sticking to the ground.

Treatment.-He was picked up and carried to his home, where the wound was cleansed thoroughly, care being taken to leave no foreign particles in it; hydrogen peroxid was used finally. The bone was replaced and the leg put in a temporary splint dressing. The subsequent treatment consisted of irrigation of the open wound and the liberal use of hydrogen peroxid.

Subsequent Bistory. - On Saturday, August 19, his father, who is a physician, told me the boy had had during the previous night what appeared to him as premonitory twitchings, and on that day, Saturday, there was slight rigidity of the museles of the neck and inability to open the mouth wide.

Antitetanic serum was ordered for him. Intraneural and intraspinal injections were advised, but were refused. The serum was given subcutaneously, and the paroxysms were controlled by hypodermics of morphin every few hours. His symptoms progressed rapidly, and death occurred at $2 \mathrm{p}$. $\mathrm{m}$. Aug. 23, 1905.

Remarks.-There is a question in my mind as to the time of inoculation in this case. Was he infected at the time of this injury or at an earlier period? About a week or ten days previous to this injury, according to the boy's mother, he stepped on a rusty nail, running it into his foot. The boy did not let his father know of this, and had his mother dress the wound, which healed promptly. He received this wound in practically the same locality in which the leg was fractured-not over 50 feet away. Was he infected with the tetanus bacillus at this time? I think it is possible, but I believe it is not probable in this case.

\section{New Instrument}

\section{MURPHY BUTTON OBTURATOR AND APPLI- CATOR.}

\section{A. H. CORDIER, M.D.,} KANSAS CITT, MO.

Having used the Murphy button for many years and having met some difficulties in its application or introduction $I$ have devised an instrument that in a great measure overcomes all the obstacles thus far met. The method usually employed heretofore to introduce the button has been to seize the rim of either half of the button with a pair of hemostats, thus forming a handle to facilitate the introduction.
On several oceasions, not only in my own work but in the work of other surgeons, the grasp of the forceps has injured the thread of the button or has dented the circumference of one-half the button so that when the two halves have been applied and were ready to be shoved together they would not fit thus necessitating the removal of the second half of the button and the introduction of a new button in the place of the one injured by the forceps. One blade of the forceps must of necessity clasp the outer side of the stem of the button so that the purse string suture is tied over the end of the forceps, thus interiering. with the proper adjustment of this suture, so that when the forceps were removed the button would drop into the intestine.

Again, while the button is being introduced the gases and other contents of the intestine are escaping thus increasing the dangers of an infection in the field of the operation. Frequently in tying the purse string around the stem of the button the mucous membrane would be crowded beyond the end of the stem so that when the approximation of the two halves was attempted this mucous membrane was found to be in the way. The forceps do not give a sufficiently. firm handle to force the button into the viscera, and to overcome the objections met with in the application of the button, I have devised an instrument to be called the Murphy button obturator and applicator. This instrument is very simple in its use and facilitates very materially the introduction of the button. It requires three sets for the three sizes of the Murphy button. The obturator that is used in the female half of the button is simply a bandle with the flange projecting where it comes in contact with the end of the stem, the portion projeeting into the button is threaded to screw into the stem of the button, thus the opening in the button is effectually closed during its introduction; there is a good firm handle to hold to and the projection rim prevents the puckering string from crowding mucous membrane beyond the stem of the button.

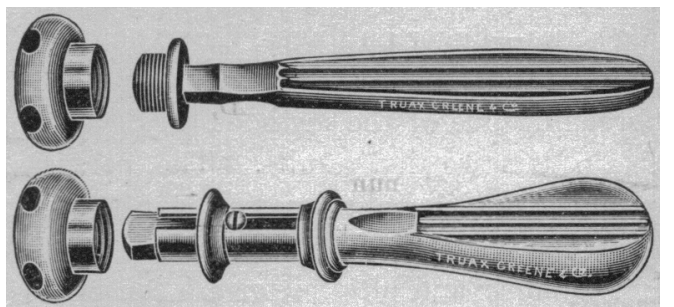

The obturator that is used in the other half of the button is composed of a hollow canula with a movable center piece. This piege at the end that is introduced in the button is wedged shape so that when the projecting portion of the canula is introduced into the half of the button and the movable piece is pulled on it spreads the slit end of the canula thus holding the button firmly. After the two halves have been introduced and are ready to be pushed together all that is necessary is to unscrew the obturator in the female part of the button and to press on the handle of the movable piece in the canula, instantly releasing the hold on the male half of the button.

The application of this instrument is far more simple than this description would seemingly imply. A reference to the accompanying illustration will give the reader a better idea of the obturator and applicator than the description.

Overlying an Infant Punished as Manslaughter in England. -Thousands of cases of death from overlying take place in Great Britain during a year. In certain cases coroners have often wished to obtain a verdict of manslaughter against the mother, but public opinion is opposed to such a course. Even in cases in which the coroner's jury has brought in this verdict it is usually set aside by the grand jury finding "no true bill." A case has at last occurred, however. in which the mother has been punishe?. At the Chester assizes oudge Phillmore sentenced a woman aged 31 years to twenty-one months' imprisonment with hard labor. Eleven days after confinement she took her child to bed with her while in a drunken state. She slept heavily and overlay and suffocated the infant. The jury found her guilty of manslanghter by an act of gross and culpable neglect. 